OPEN ACCESS

Edited by:

Abhay P. S. Rathore,

Duke University, United States

Reviewed by:

Ashley L. St John

Duke-NUS Medical School,

Singapore

Stephen Kent,

The University of Melbourne, Australia

*Correspondence:

David H. O'Connor

dhoconno@wisc.edu

Specialty section:

This article was submitted to

Viral Immunology,

a section of the journal

Frontiers in Immunology

Received: 26 March 2021

Accepted: 04 May 2021

Published: 17 May 2021

Citation:

Newman CM, Tarantal AF,

Martinez ML, Simmons HA, Morgan TK, Zeng X, Rosinski JR, Bliss MI, Bohm EK, Dudley DM, Aliota MT, Friedrich TC, Miller CJ and O'Connor DH (2021) Early

Embryonic Loss Following Intravaginal Zika Virus Challenge in Rhesus Macaques.

Front. Immunol. 12:686437. doi: 10.3389/fimmu.2021.686437

\section{Early Embryonic Loss Following Intravaginal Zika Virus Challenge in Rhesus Macaques}

\author{
Christina M. Newman ${ }^{1}$, Alice F. Tarantal ${ }^{2,3}$, Michele L. Martinez ${ }^{2,3}$, Heather A. Simmons ${ }^{4}$, \\ Terry K. Morgan ${ }^{5}$, Xiankun Zeng ${ }^{6}$, Jenna R. Rosinski ${ }^{1}$, Mason I. Bliss ${ }^{7}$, Ellie K. Bohm ${ }^{8}$, \\ Dawn M. Dudley ${ }^{1}$, Matthew T. Aliota ${ }^{8}$, Thomas C. Friedrich ${ }^{7}$, Christopher J. Miller $^{3,9}$ \\ and David H. O'Connor ${ }^{1,4 *}$ \\ ${ }^{1}$ Pathology and Laboratory Medicine, University of Wisconsin-Madison, Madison, WI, United States, ${ }^{2}$ Pediatrics, Cell \\ Biology and Human Anatomy, School of Medicine, University of California, Davis, CA, United States, ${ }^{3}$ California National \\ Primate Research Center, University of California, Davis, CA, United States, ${ }^{4}$ Wisconsin National Primate Research Center, \\ University of Wisconsin-Madison, Madison, WI, United States, ${ }^{5}$ Pathology, Oregon Health and Sciences University, Portland, \\ OR, United States, 6 Pathology Division, United States Army Medical Research Institute of Infectious Diseases, Frederick, \\ MD, United States, ${ }^{7}$ Pathobiological Sciences, University of Wisconsin-Madison, Madison, WI, United States, ${ }^{8}$ Veterinary \\ and Biomedical Sciences, University of Minnesota, Saint Paul, MN, United States, ${ }^{9}$ Pathology, Microbiology, and \\ Immunology, School of Veterinary Medicine, Center for Immunology and Infectious Diseases, University of California, \\ Davis, CA, United States
}

Zika virus (ZIKV) is an arthropod-borne virus (arbovirus) and is primarily transmitted by Aedes species mosquitoes; however, ZIKV can also be sexually transmitted. During the initial epidemic and in places where ZIKV is now considered endemic, it is difficult to disentangle the risks and contributions of sexual versus vector-borne transmission to adverse pregnancy outcomes. To examine the potential impact of sexual transmission of ZIKV on pregnancy outcome, we challenged three rhesus macaques (Macaca mulatta) three times intravaginally with $1 \times 10^{7} \mathrm{PFU}$ of a low passage, African lineage ZIKV isolate (ZIKV-DAK) in the first trimester ( $\sim 30$ days gestational age). Samples were collected from all animals initially on days 3 through 10 post challenge, followed by twice, and then once weekly sample collection; ultrasound examinations were performed every 3-4 days then weekly as pregnancies progressed. All three dams had ZIKV RNA detectable in plasma on day 3 post-ZIKV challenge. At approximately 45 days gestation (17-18 days postchallenge), two of the three dams were found with nonviable embryos by ultrasound. Viral RNA was detected in recovered tissues and at the maternal-fetal interface (MFI) in both cases. The remaining viable pregnancy proceeded to near term ( 155 days gestational age) and ZIKV RNA was detected at the MFI but not in fetal tissues. These results suggest that sexual transmission of ZIKV may represent an underappreciated risk of pregnancy loss during early gestation. 


\section{INTRODUCTION}

Zika virus (ZIKV) emerged from relative obscurity five years ago to sweep through tropical and subtropical regions of the Western hemisphere. More than a million cases between 2015 and 2018 were reported in Pan American Health Organization (PAHO) regions alone (1). While ZIKV primarily causes mild febrile illness or asymptomatic infections in a majority of individuals, infection during pregnancy can result in a range of adverse outcomes including fetal loss and a constellation of birth defects now known as congenital Zika syndrome (CZS) (2-4). Human infection with ZIKV can occur following mosquito-borne, vertical, and sexual transmission (5-7). While mosquito-borne transmission from infected Aedes species mosquitoes is thought to be the most common route of infection in endemic areas, the contribution of sexual transmission in epidemics remains poorly understood, in part because during an outbreak, both transmission routes occur simultaneously and can be challenging to disentangle (8).

Sexual transmission of ZIKV was first documented in 2008 when a scientist working in Senegal became infected and, upon his return to the United States, infected his wife (9). Throughout the ZIKV outbreak in 2015 and 2016, additional sexuallytransmitted infections were documented (10-14). The majority of sexually-transmitted cases in non-endemic areas are likely the result of infection of the primary cases during travel, followed by inadvertent transmission to the secondary cases upon returning home (7). As previously mentioned, sexually-transmitted ZIKV infections in endemic areas or areas experiencing active outbreaks are difficult to differentiate from mosquitotransmitted infections because there may be an individual risk of exposure by either route. Epidemiological data suggest that sexual transmission occurs primarily male-to-female through vaginal contact, even weeks after clinical symptom resolution, which suggests that sexual transmission of ZIKV does pose at least a theoretical risk to pregnant women (15). Furthermore, the ZIKV viral RNA (vRNA) load in human semen has been reported to range from the hundreds to tens of millions of copies per milliliter, with values as high as $3.98 \times 10^{8}$ copies $/ \mathrm{ml}$ reported (16-18). The testes in particular, were found to be a ZIKV reservoir in animal models $(19,20)$. In addition, studies have recently shown that intimate partners of household index cases are more likely to also be positive or show serologic evidence of ZIKV infection relative to other members of the same household (21).

Overall, we have limited information regarding the risk of ZIKV sexual transmission to pregnant women and their developing fetuses (14). Studies have shown that other sexually transmitted ascending vaginal infections are associated with an increased risk of pre-term labor and other poor outcomes (22). Whether an ascending intravaginal ZIKV infection poses a higher risk to pregnancy than mosquito-borne infection is currently unknown. Pregnant women or women trying to become pregnant may be less likely to utilize condoms, a recommended strategy for the prevention of sexual transmission of ZIKV $(23,24)$. Furthermore, a woman might not be aware of a pregnancy during early gestation and unfortunately, existing data suggest that the highest risk for developmental anomalies associated with ZIKV infection is during the first trimester, a critical developmental time period (25-27). Additionally, ZIKV infection during pregnancy has also been associated with an increased risk for spontaneous abortion in both humans and nonhuman primates $(28,29)$.

Animal models have played a critical role in improving our understanding of the natural history and pathogenesis of ZIKV. To-date, both murine and nonhuman primate (NHP) models have been utilized to examine aspects of sexual transmission of ZIKV (19, 20, 30, 31). Studies in these models have shown persistent shedding of vRNA from the reproductive tract, infection of the female reproductive tract via a vaginal exposure route, and fetal effects as a result of vaginal exposure or sexual transmission in mice (20,30-39). Although studies in pregnant olive baboons have shown that intravaginal challenge with infected baboon semen during mid-gestation can result in productive maternal infection and vRNA detection in some maternal tissues and placentas, to date, studies in NHP have not shown clear evidence of vertical transmission associated with maternal ZIKV infection by the intravaginal route (33).

Because infection during the first trimester is associated with the highest risk for adverse pregnancy outcomes and, since women may be unaware of a pregnancy and may potentially be less likely to utilize barrier methods to prevent sexuallytransmitted ZIKV infections during the early first trimester (23, $24)$, we designed a proof-of-concept study in which we challenged three gravid rhesus macaques (Macaca mulatta) intravaginally with ZIKV. Our goal was to investigate the potential impact of intravaginal ZIKV challenge during the first trimester on fetal and pregnancy outcomes and to develop a model for sexual transmission during early pregnancy.

\section{METHODS}

\section{Ethics Statement}

All animal procedures conformed to the requirements of the Animal Welfare Act and protocols were approved prior to implementation by the Institutional Animal Care and Use Committee (IACUC) at the University of California, Davis. Activities related to animal care, housing, and diet were performed according to California National Primate Research Center (CNPRC) standard operating procedures (SOPs). SOPs for colony related procedures are reviewed and approved by the UC Davis IACUC.

\section{Study Design}

Female rhesus macaques (Macaca mulatta, $\mathrm{N}=3$ ) were timemated and identified as pregnant by ultrasound according to established methods (40). Prior to study assignment normal embryonic growth and development were confirmed by ultrasound. Females were challenged in the first trimester at approximately 30 days gestational age (trimesters divided by 55 day increments; term $165 \pm 10$ days) with $1 \times 10^{7}$ PFU ZIKV-DAK three times intravaginally at approximately two-hour intervals 
(Table 1 and Figure 1). Pregnancies were monitored by ultrasound every 3-4 days post-challenge and then weekly from day 50 onward throughout the study period. Standardized parameters were assessed including fetal growth (greatest length then biparietal and occipitofrontal diameters, head and abdominal circumferences, humerus and femur lengths) and structural development, amniotic fluid volumes and placental parameters, and compared to normal growth and developmental trajectories for the species (40). Dams were weighed at each sedation and blood samples were collected daily from day 3 through day 10 post-challenge, followed by bi-weekly until maternal plasma vRNA loads were undetectable, and then weekly until hysterotomy. Plasma and peripheral blood mononuclear cells (PBMCs) were isolated at all time points, and serum was collected on days 0,14 , and 24 post-challenge (dams 049-102 and 049-103), and on days 0, 14, 27, and 122 post-challenge for dam 049-101. Urine was collected by ultrasound-guided cystocentesis $(\sim 1 \mathrm{ml})$ on days $7,10,14,21$, and 24 post-challenge (dams 049-102 and 049-103) and on days $7,10,14,27$, and 122 post-challenge for dam 049-101. Hysterotomies were performed for dam 049-102 and 049-103 at the end of the first trimester (post-detection of nonviable embryos by ultrasound) and near term ( 155 days gestational age) for dam 049-101.

\section{Virus Challenge Preparation and Infection} ZIKV strain Zika virus/A.africanus-tc/Senegal/1984/DAK AR 41524 (ZIKV-DAK; GenBank: KX601166) was originally isolated from Aedes luteocephalus mosquitoes in Senegal in 1984. One round of amplification on Aedes pseudocutellaris cells, followed by amplification on C6/36 cells and two rounds of amplification on Vero cells, were used to prepare a master stock obtained from BEI Resources (Manassas, VA). Challenge stocks were prepared from this master stock by inoculation onto a confluent monolayer of C6/36 mosquito cells as described previously (41). Prior to administration, the ZIKV-DAK stock was diluted to $1 \times 10^{7} \mathrm{PFU}$ in $1 \mathrm{ml}$ sterile saline and delivered via a $1 \mathrm{ml}$ tuberculin syringe (37). Animals were inoculated three times intravaginally under ketamine sedation at approximately two-hour intervals using a previously described method (37).

\section{Blood Processing and Plasma vRNA Loads}

Plasma and PBMCs were isolated from blood placed in EDTA vacutainers and processed at 1500 RPM for 15 minutes according to standard protocols. Serum was isolated from whole blood collected into glass vacutainers without additives. Viral RNA was extracted from $300 \mu$ l plasma as previously described with a Maxwell $16 \mathrm{MDx}$ instrument (Promega, Madison, WI) and evaluated using qRT-PCR (42). RNA concentration was determined by interpolation onto an internal standard curve of seven ten-fold serial dilutions of a synthetic ZIKV RNA segment based on Zika virus/Human/ French Polynesia/10087PF/2013 (ZIKV-FP). The limit of quantification of the ZIKV qRT-PCR assay is estimated to be 100 copies $v R N A / m l$ plasma or serum.

\section{Hysterotomy and Tissue Collection}

Dams 049-102 and 049-103 were scheduled for hysterotomies in the late first trimester (nonviable embryos detected 3 days prior to hysterotomy). The hysterotomy for dam 049-101 was performed at approximately 155 days gestational age according

TABLE 1 | Dam information on day 0 of study.

\begin{tabular}{|c|c|c|c|c|c|c|c|}
\hline Dam ID & Weight (kg) & Age (y) & Gestational Age (days) & Scheduled hysterotomy (days) & Virus & Dose (PFU) & Challenge \# \\
\hline 049-101 & 5.55 & 6.93 & 29 & 155 & ZIKV-DAK & $1 \times 10^{7}$ & 3 \\
\hline 049-102 & 7.40 & 11.83 & 32 & 155 & ZIKV-DAK & $1 \times 10^{7}$ & 3 \\
\hline $049-103$ & 8.43 & 12.83 & 31 & 155 & ZIKV-DAK & $1 \times 10^{7}$ & 3 \\
\hline
\end{tabular}

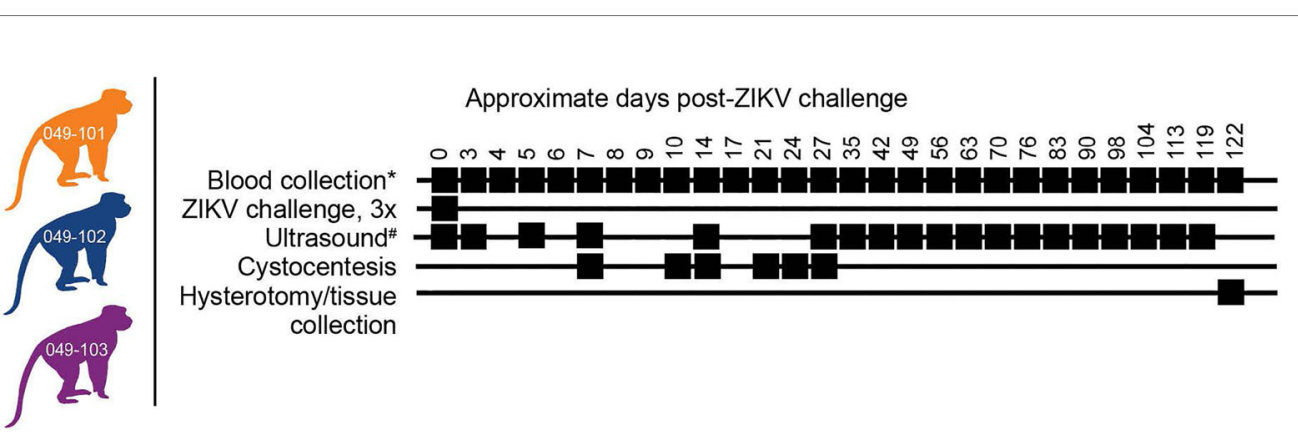

FIGURE 1 | Study design. Three female rhesus macaques were time-mated, confirmed pregnant by ultrasound, and challenged intravaginally at 30 days (+/-2) gestational age with $1 \times 10^{7}$ PFU ZIKV-DAK three times at two-hour intervals. Blood collection* denotes plasma and PBMC isolation at every sampling time point while serum collection was planned only on days $0,14,27$, and 122 post-ZIKV challenge. Ultrasound ${ }^{\#}$ denotes ultrasound imaging was performed every 3-4 days during early gestation, then weekly thereafter. Hysterotomies were originally planned for each animal at approximately 122 days post-ZIKV challenge. 
to the original study design (Figure 1) and following established protocols (43). The gestational sac was removed for fetal tissue assessments, with a modified collection protocol for nonviable specimens (see below). For the fetus from dam 049-101 amniotic fluid, fetal blood, and fetal cerebrospinal fluid were collected, then fetal body weights and measures (biparietal and occipitofrontal diameters, abdominal and arm circumferences, hand and foot lengths, humerus and femur lengths, crown-rump length) were assessed. The left cerebral hemisphere and left eye were collected under aseptic conditions and shipped with cold packs to Wisconsin by overnight delivery for additional assessments (see below). Specimens collected for qRT-PCR for vRNA analysis included dura mater; right cerebral hemisphere (frontal, parietal, temporal, occipital lobes); cerebellum (right and left) and midbrain; right optic nerve; right eye (cornea, retina, sclera); spinal cord (cervical, thoracic, lumbar); right and left parotid glands, submandibular, and salivary glands; omentum; thymus; spleen; liver (right, left, quadrate, caudate lobes); pancreas; right and left adrenal glands and kidneys; right and left axillary and inguinal lymph nodes; diaphragm; tracheobronchial and mesenteric lymph nodes; right and left thyroids; trachea; esophagus; pericardium; aorta; right and left atria and ventricles; lung lobes (right and left; all lobes); reproductive tract including right and left gonads; urinary bladder; gastrointestinal tract (stomach, duodenum, jejunum, ileum, colon; meconium), skin, skeletal muscle, and bone marrow (Table 2). The placenta was weighed and assessed including disk measurements (primary and secondary for bidiscoid placentas; primary disk only for monodiscoid), umbilical cord and membrane insertion sites, blood vessel distribution, cut surfaces, and examined for the presence of infarcts. Decidua, membranes, umbilical cord, and multiple sections of the placental disks were collected. All specimens were quick frozen in triplicate over liquid nitrogen for qRT-PCR analysis or collected into RNAlater (cat\# R0901, Sigma-Aldrich, St. Louis, MO). Multiple blocks of tissues were collected in histology cassettes fixed in $10 \%$ buffered formalin, embedded, sectioned (5-6 $\mu \mathrm{m})$ and stained with hematoxylin and eosin (H\&E) or used for in situ hybridization (ISH).

For dams 049-102 and 049-103 a modified collection was performed, consistent with the early developmental stage of the conceptus (Table 2). Decidua, membranes, umbilical cord, and multiple sections of the placental disks were collected as noted above.

Fresh samples collected from the 049-101 fetus (left cerebral hemisphere and left eye) were shipped with cold packs for additional assessments as noted above; the eye was analyzed by the Comparative Ocular Pathology Laboratory of Wisconsin

TABLE 2 | Fetal and maternal-fetal interface tissues collected at hysterotomy.

\begin{tabular}{|c|c|c|c|c|}
\hline Dam ID & Organ System/Tissue & Tissue samples tested $(\mathrm{N})$ & Tissue samples qRT-PCR positive (N) & Positive tissue vRNA copies/mg ( \pm SD) \\
\hline & musculoskeletal & 2 & 0 & 0.0 \\
\hline & nervous & 14 & 0 & 0.0 \\
\hline & lymphatic & 8 & 0 & 0.0 \\
\hline & cardiovascular & 4 & 0 & 0.0 \\
\hline & respiratory & 10 & 0 & 0.0 \\
\hline & reproductive & 3 & 0 & 0.0 \\
\hline & other & 8 & 0 & 0.0 \\
\hline & primary placental disk & 3 & 2 & $0.66 \times 10^{2 a}\left( \pm 0.51 \times 10^{2}\right)$ \\
\hline & primary placental disk & 3 & 3 & $1.59 \times 10^{3 a}\left( \pm 1.20 \times 10^{3}\right)$ \\
\hline & placenta with decidua & 18 & 3 & $8.13 \times 10^{2 a}\left( \pm 3.97 \times 10^{2}\right)$ \\
\hline & placenta without decidua & 18 & 6 & $6.45 \times 10^{2 a}\left( \pm 6.10 \times 10^{2}\right)$ \\
\hline & membranes & 1 & 1 & $4.87 \times 10^{3}$ \\
\hline & primary placental disk & 3 & 3 & $4.96 \times 10^{3 a}\left( \pm 4.00 \times 10^{3}\right)$ \\
\hline & secondary placental disk & 3 & 3 & $3.61 \times 10^{3 a}\left( \pm 1.16 \times 10^{3}\right)$ \\
\hline & decidua & 1 & 0 & 0.0 \\
\hline \multirow[t]{9}{*}{ 049-103 } & nervous (brain) & 1 & 1 & $1.74 \times 10^{5}$ \\
\hline & digestive (liver) & 1 & 1 & $7.42 \times 10^{4}$ \\
\hline & umbilical cord & 1 & 1 & $7.13 \times 10^{4}$ \\
\hline & amnion & 1 & 1 & $7.08 \times 10^{2}$ \\
\hline & chorionic jelly & 1 & 1 & $3.54 \times 10^{3}$ \\
\hline & membranes (amnion and chorion) & 1 & 1 & $4.74 \times 10^{3}$ \\
\hline & primary placental disk & 3 & 3 & $1.98 \times 10^{3 a}\left( \pm 1.13 \times 10^{3}\right)$ \\
\hline & secondary placental disk & 3 & 3 & $3.40 \times 10^{3 a}\left( \pm 2.18 \times 10^{3}\right)$ \\
\hline & decidua & 1 & 0 & 0.0 \\
\hline
\end{tabular}

${ }^{a}$ mean vRNA load of multiple positive tissue samples. 
(COPLOW). Placental tissues from all dams and tissues for the fetus from dam 049-101 were assessed as described previously in Koenig et al. (44).

\section{Tissue, Urine, and Amniotic Fluid vRNA Loads}

Maternal-fetal interface (MFI) and fetal tissue vRNA loads were determined from approximately $20 \mathrm{mg}$ of each specimen. ZIKV RNA was isolated from tissues using the Qiagen AllPrep DNA/ RNA Mini Kit (cat\# 80284, Qiagen, Germantown MD) using the QIAcube following the manufacturer's protocol. Viral RNA was isolated from $140 \mu \mathrm{l}$ maternal urine or amniotic fluid using the QIAmp Viral RNA minikit (cat\# 52904, Qiagen, Germantown $\mathrm{MD)}$ following the manufacturer's protocol. Following isolation, cDNA synthesis was performed using the Qiagen Sensiscript RT kit (cat\# 205213, Qiagen, Germantown MD) according to the manufacturer's protocol. Quantification of vRNA load was performed by real-time PCR using the Taqman amplification system and the QuantStudio $12 \mathrm{~K}$ Flex Real-Time PCR System (ThermoFisher Scientific, Grand Island, NY) as described previously (43). The estimated limit of quantification of the assay is $50-100 \mathrm{ZIKV} \mathrm{RNA} \mathrm{copies/mg} \mathrm{tissue} \mathrm{(average}=75$ copies $/ \mathrm{mg}$ ).

\section{In Situ Hybridization (ISH)}

ISH probes against the ZIKV genome were commercially purchased (cat\# 468361, Advanced Cell Diagnostics, Newark, CA). ISH was performed using the RNAscope ${ }^{\circledR}$ Red 2.5 kit (cat\# 322350, Advanced Cell Diagnostics, Newark, CA) according to the manufacturer's protocol. After deparaffinization with xylene, a series of ethanol washes, and peroxidase blocking, sections were heated with the antigen retrieval buffer and then digested by proteinase. Sections were then exposed to the ISH target probe and incubated at $40^{\circ} \mathrm{C}$ in a hybridization oven for two-hours. After rinsing, ISH signal was amplified using the provided preamplifier followed by the amplifier-containing labelled probe binding sites, and developed with a Fast Red chromogenic substrate for 10 minutes at room temperature. Sections were then stained with hematoxylin, air-dried, and mounted.

\section{Plaque Reduction Neutralization Tests (PRNT)}

Titers of ZIKV neutralizing antibodies were determined using plaque reduction neutralization tests (PRNT) on Vero cells (ATCC \#CCL-81) with a cutoff value of 90\% (PRNT 90 ) (45). Neutralization curves were generated in GraphPad Prism (San Diego, CA) and the resulting data were analyzed by nonlinear regression to estimate the dilution of serum required to inhibit $90 \%$ Vero cell culture infection $(45,46)$.

\section{RESULTS}

\section{Repeated Intravaginal ZIKV Challenge Results in Infection In Pregnant Macaques}

All three dams had detectable ZIKV RNA in plasma by 3 days post intravaginal ZIKV challenge (Figure 2). ZIKV RNA loads peaked on day 5 for dams 049-101 and 049-102, and on day 6 for dam 049-103. Peak vRNA loads ranged from $1.57 \times 10^{4}$ copies $/ \mathrm{ml}$ for $049-101$ to $1.30 \times 10^{5}$ copies $/ \mathrm{ml}$ for $049-103$ (Figure 2). The latest detectable plasma vRNA load for animal 049-101 was on day 24 post-challenge $\left(1.56 \times 10^{2}\right.$ copies/ml). Dam 049-103 had a detectable plasma vRNA load until day $14\left(2.46 \times 10^{3}\right.$ copies $\left./ \mathrm{ml}\right)$ but was negative on day 17 (the next time point samples were collected). Dam 049-102 was consistently positive for ZIKV vRNA until day 14, was negative on day 17, and then positive again on days 21 and 24 post challenge. Dam 049-102 was positive for ZIKV RNA in blood plasma collected at hysterotomy, the last time point sampled for the study. Overall, maternal plasma vRNA loads for dams 049-101, 049102, and 049-103 were somewhat delayed compared to animals subcutaneously inoculated with French Polynesian or Puerto Rican ZIKV isolates in our previous studies, but were consistent in magnitude with previous observations $(42,48,49)$. In addition, maternal plasma vRNA loads peaked within a time period similar to subcutaneously inoculated animals infected with the same ZIKV isolate (ZIKV-DAK) (47) (Figure 2).

\section{Embryonic Demise Following Intravaginal ZIKV Infection During Early Pregnancy}

Ultrasound examinations indicated that the embryos of dams 049-102 and 049-103 were nonviable at approximately 17-18 days post-challenge. Hysterotomies were subsequently scheduled and performed and each dam's final blood and urine samples were collected (Figure 3A). Embryo and placental tissues from dams 049-102 and 049-103 were collected for vRNA analysis, histopathological assessment, and ISH. Dam 049-101's pregnancy progressed normally and sampling continued until the study endpoint and near-term hysterotomy at approximately 155 days gestational age (Figure 3A). All fetal and placental measurements for 049-101 were recorded and were considered within normal limits for gestational age (Table 3) (40).

\section{MFI, Tissues, and Amniotic Fluid Are ZIKV RNA Positive in Nonviable Embryos}

ZIKV RNA was detected in the amniotic fluid from the conceptus of both dams $049-102$ and $049-103$ at $3.87 \times 10^{3}$ and $7.38 \times 10^{3}$ copies $/ \mathrm{ml}$ respectively at the time of hysterotomy (subsequent to embryonic death). In addition, ZIKV RNA was detected in the brain and liver of both non-viable embryos, as well as in MFI tissues including the primary and secondary placental disks and membranes (amnion and chorion) (Figure 3B). The highest tissue vRNA burden was detected in the brain of the embryo from dam 049-102 (1.74 $10^{5}$ copies/mg). ZIKV RNA was not detected in amniotic fluid collected from the fetus of dam 049-101 at hysterotomy. Although a large number of fetal and MFI tissues were assessed following hysterotomy, the presence of ZIKV RNA was only detected in a subset of sections of MFI tissues from 049-101 (Table 2 and Figure 3C). The decidua from all three dams were negative for ZIKV RNA by qRT-PCR. Similarly, ZIKV RNA was not detected in the urine for any of the dams at any of the time points sampled. Overall, these results highlight the focal nature of ZIKV RNA detection in 


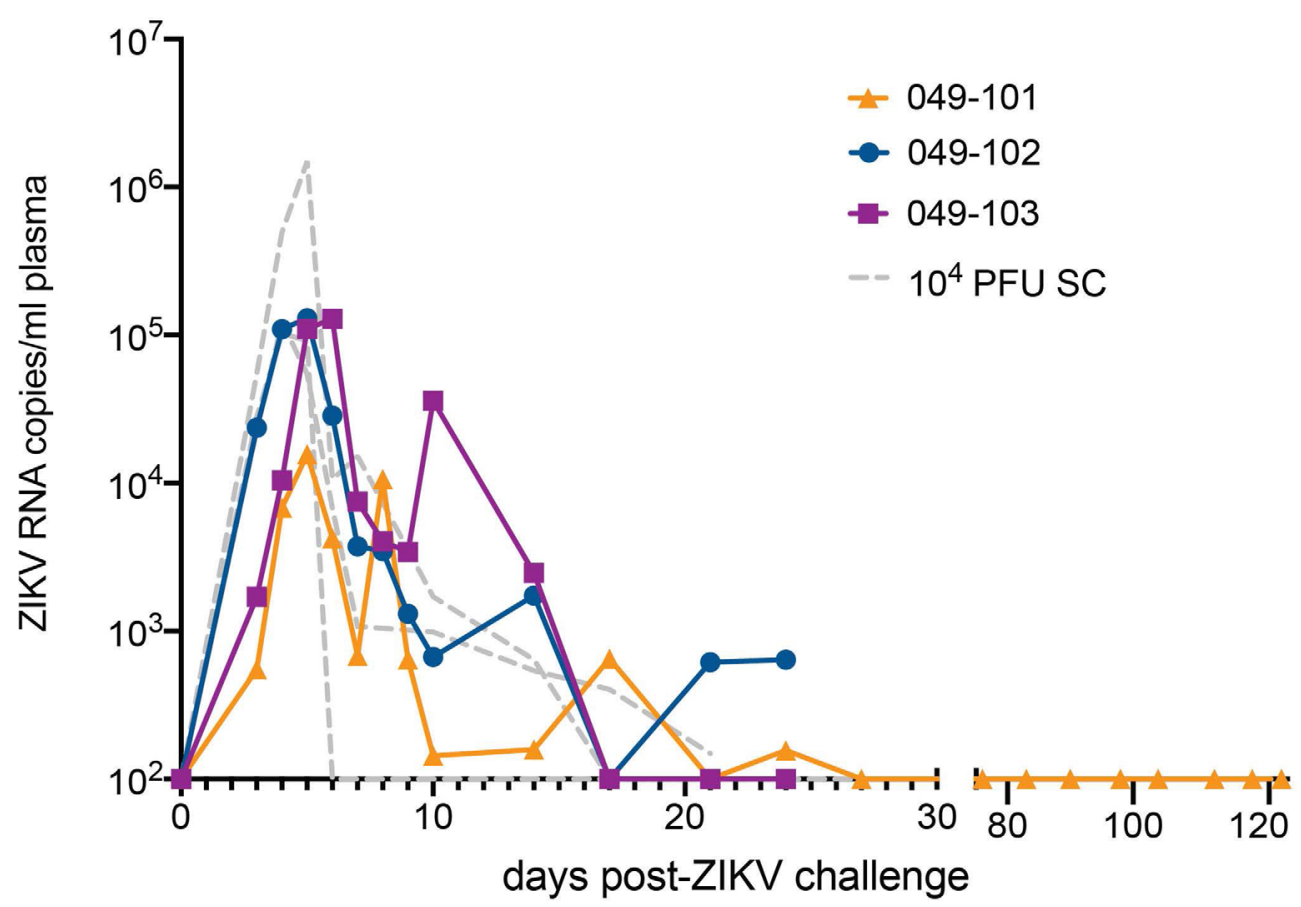

FIGURE 2 | Intravaginal ZIKV challenge resulted in detection of VRNA in plasma for all three dams. The x-axis shows days post-ZIKV challenge. The y-axis starts at the estimated limit of quantification of the qRT-PCR assay $\left(1 \times 10^{2}\right.$ copies/ml) and is shown as copies/ml plasma on the log scale. Plasma vRNA loads are displayed for dam 049-101 as orange triangles, for dam 049-102 as blue circles, and for dam 049-103 as magenta squares. For comparison, ZIKV plasma vRNA loads are also shown for three pregnant macaques subcutaneously (SC) inoculated with $1 \times 10^{4} \mathrm{PFU}$ ZIKV-DAK and are displayed as gray dashed lines and noted as $10^{4}$ PFU $\mathrm{SC}$ in the legend (47).

fetal and MFI tissues following infection during pregnancy. For a number of tissues, multiple samples were collected for vRNA analysis but ZIKV was only detected in a subset of those samples (Table 2).

\section{Changes in Placental Tissues Following Intravaginal ZIKV Infection Are Non-Specific}

Histopathological assessments of the placentas of dams 049-102 and 049-103 following embryonic demise showed generalized, non-specific mild necrosis (Table 4 and Supplemental Figures 1-3). In particular, the secondary placental disk from dam 049-102 showed intervillous hemorrhage and parenchymal ischemia (Supplemental Figures 2A, B). In addition, the decidua from dam 049-102 showed some evidence of minimal focal necrosis (Supplemental Figure 2C). Placentas from both dam 049-102 and dam 049-103 had minimal to mild multifocal villous mineralization. The secondary placental disk of dam 049-103 showed acute neutrophilic inflammation, mild focal ischemia, and hemorrhage (Supplemental Figure 3B). Similar to the placentas from the other two dams, the placenta of dam 049-101 showed mild, multifocal villous mineralization, findings which have previously been observed in control placentas. Focal hemorrhage of the primary placental disk basal plate was also noted for dam 049-101 (Supplemental Figure 1A). In addition, decidual tissue from dam 049-101 showed mild, multifocal muscularization of the decidual arteries (Supplemental Figure 1B). Overall, changes in the placental tissues were mild and not associated with any specific pathological processes. Assessment of fetal tissues from dam 049-101 showed normal brain and eye morphology with no identified lesions.

\section{ZIKV Genomic RNA Is Detected in MFI Tissues From Demise Cases but Not From the Near-Term Pregnancy}

Tissue sections from decidua, primary placental disks, and secondary placental disks (bidiscoid placentas) were assessed by ZIKV ISH using RNAscope (see Methods). ZIKV genomic RNA was detected in both the primary and secondary placental disks from dams 049-102 and 049-103 (Figure 4). No ZIKV RNA was detected by RNAscope in the primary placental disk from dam 049-101, nor any of the decidua sections from any of the pregnancies. The lack of ZIKV RNA in the decidua sections by ISH was consistent with the tissue vRNA assessment by qRT-PCR.

\section{Animals Infected Intravaginally With ZIKV During Pregnancy Develop Neutralizing Antibodies}

Serum neutralizing antibody titers (nAbs) against ZIKV were evaluated for dams 049-102 and 049-103 on days 0, 14, and 24 


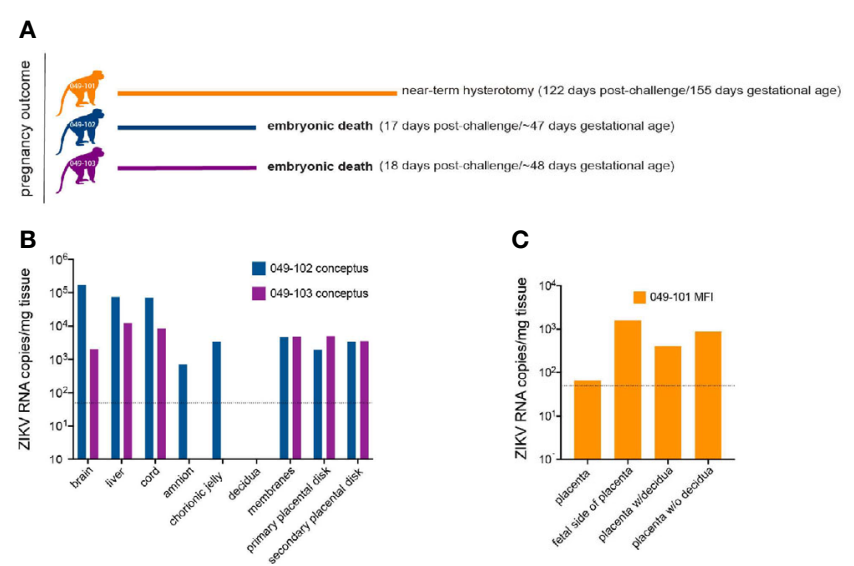

FIGURE 3 | Pregnancy outcomes and maternal-fetal interface (MFI) and fetal tissue vRNA loads. (A) Pregnancy outcomes for three dams intravaginally inoculated 3x with ZIKV at approximately 30 days gestation. Two dams (049-102 and 049-103) were determined by ultrasound to have nonviable embryos at approximately 17-18 days post-ZIKV challenge. Hysterotomies and embryo and MFI tissue collections were performed 3 days after detection. Dam 049-101's pregnancy continued until scheduled hysterotomy and extensive tissue collection at approximately 155 days gestational age. (B) Average ZIKV vRNA loads for positive embryo and MFI tissues collected at hysterotomy from dams 049-102 (blue) and 049-103 (magenta) following embryonic death at approximately 17-18 days post-ZIKV challenge. The dashed line represents the average of the estimated limit of detection (50-100 copies/mg, average: 75 copies/mg tissue) for the qRT-PCR assay. (C) Average ZIKV VRNA loads for positive MFI tissues collected at hysterotomy from dam 049-101 (orange) at approximately 122 days post-ZIKV infection. Fetal tissues were negative for ZIKV RNA by qRT-PCR. The dashed line represents the average of the estimated limit of detection (50-100 copies/mg, average: 75 copies/mg tissue) for the qRT-PCR assay.

TABLE 3 | 049-101 fetal and placental measurements ( 155 days gestation, 122 days post challenge).

\begin{tabular}{lcc}
\hline Tissue & Measure $\mathbf{( m m )}$ & Weight (g) \\
\hline whole body & 180.0 & 405.75 \\
biparietal diameter & 52.3 & - \\
head circumference & 186.0 & - \\
r./l. femur & $52.8 / 53.0$ & - \\
brain & - & 54.42 \\
cerebrum & - & 50.2 \\
cerebellum with midbrain & - & 3.31 \\
cerebellum without midbrain & - & 2.47 \\
r./l. eye & $13.6 / 13.8$ & $1.34 / 1.35$ \\
r./l. thyroid & - & $0.07 / 0.07$ \\
thymus & - & 1.42 \\
spleen & - & 0.58 \\
liver & - & 12.08 \\
r./l. adrenal & - & $0.12 / 0.17$ \\
r./l. kidney & - & $1.00 / 0.99$ \\
lung lobes & - & 8.76 \\
r./l. testis & - & $0.06 / 0.06$ \\
placenta & $145.0 \times 85.0$ & 159.19 \\
\hline
\end{tabular}

Measurements were considered to be within normal limits by ultrasound and gross assessment (40). R, right; $L$, left.

post-challenge by $90 \%$ plaque reduction neutralization tests $\left(\mathrm{PRNT}_{90}\right)$. Serum samples from $0,14,27$, and 122 days postchallenge collected from dam 049-101 were similarly assessed. Samples collected on day 0 (pre-challenge) from all animals were negative for ZIKV nAbs. Neutralizing Ab titers above 1:10 are indicative of immunity against ZIKV. Serum collected on day 14 post-challenge from all animals neutralized ZIKV-DAK at levels considered protective by $\mathrm{PRNT}_{90}$ (between 1:100 and 1:1000 for each animal). Serum collected on day 24 post-challenge from dams 049-102 and 049-103, and on day 27 post-challenge from dam 049-101 showed an increased neutralization response relative to baseline (day 0) and day 14 for each individual animal (Figure 5). By day 122 post-challenge, the ZIKV nAb response for animal $049-101$ was lower than on days 14 or 27, but still demonstrated a strong protective response (PRNT $_{90}$ titer approximately 1:300) (Figure 5). These results suggest that all animals developed a $\mathrm{nAb}$ response against ZIKV following intravaginal ZIKV challenge consistent with findings previously noted for rhesus dams infected subcutaneously (42, 48, 49).

\section{DISCUSSION}

Here we describe a proof-of-concept study that indicates intravaginal challenge with ZIKV during early pregnancy results in productive maternal infection and suggests that infection by this route can result in embryonic demise. ZIKV RNA was detected at the MFI and in embryonic tissues, as well as in the amniotic fluid from the pregnancies of dams 049-102 and 049-103, supporting a role for ZIKV in the adverse pregnancy outcomes for these animals. Although ZIKV was detected by qRT-PCR in the MFI tissues from dam 049-101, no vRNA was detected in fetal tissues directly. Interestingly, although vRNA was detectable in the placenta of dam 049-101 by qRT-PCR, it was not detected by ISH. Given the focal nature of ZIKV RNA detected in the placental tissue samples collected from dam 049101, it is likely that the samples evaluated by ISH were simply from areas without vRNA present (Table 2). In order to assess 
TABLE 4 | Histopathological assessment of placental tissues from all animals and fetal tissues from 049-101.

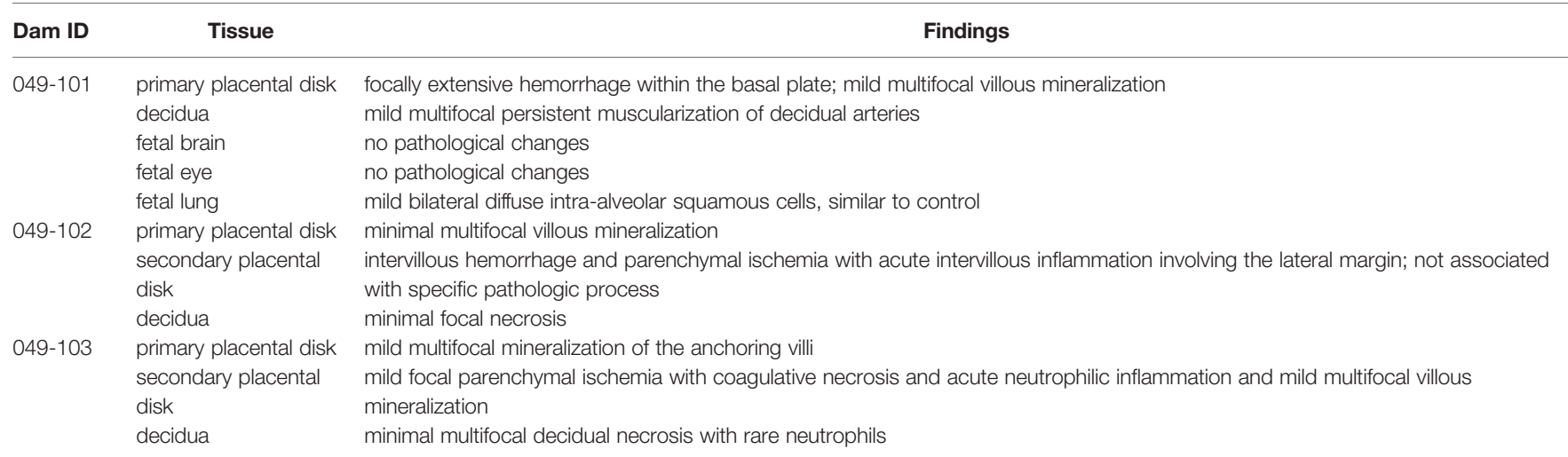

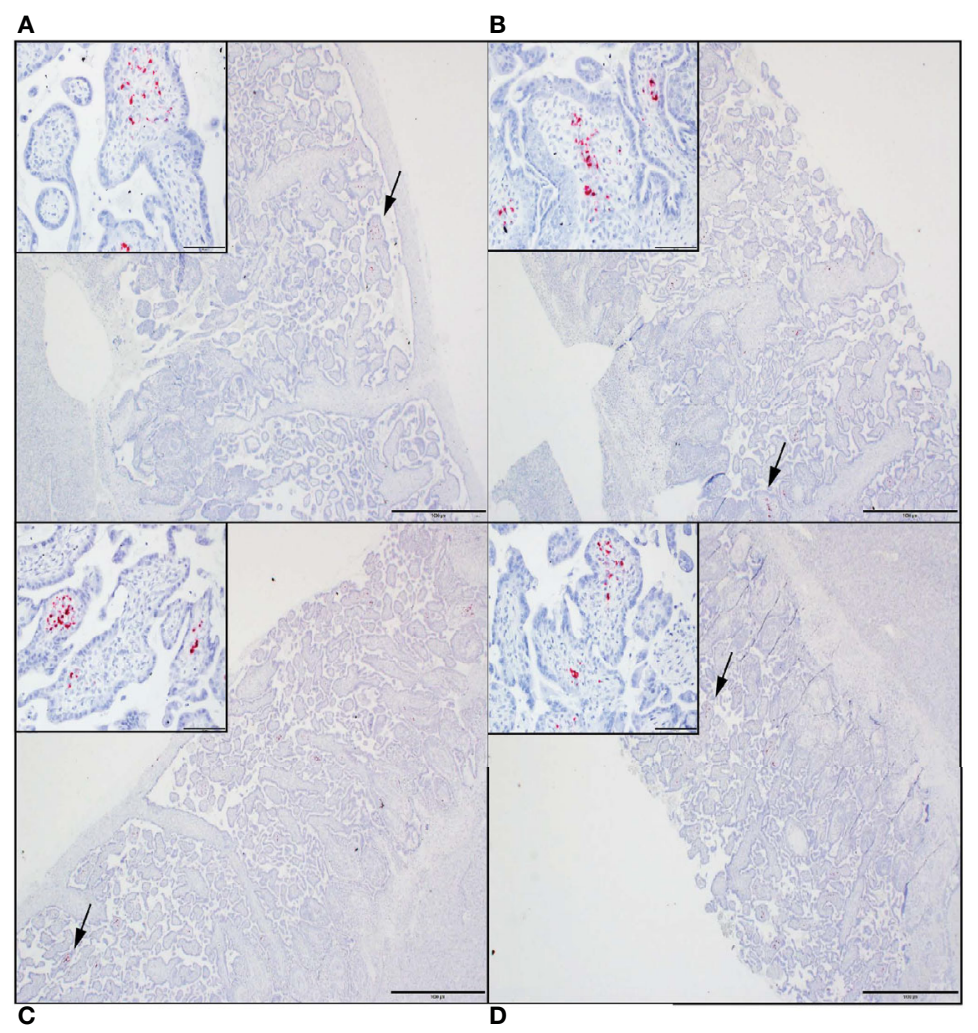

FIGURE 4 | ZIKV genomic RNA was detected by in situ hybridization (ISH) in placental tissues collected from dams 049-102 and 049-103, but not from dam 049101. For all images, red coloration is indicative of positive staining for ZIKV genomic RNA. Overall, positive staining is focal but visible in multiple areas. Insets show high magnification of the areas denoted by the black arrows in each larger panel. Representative images are shown of (A) primary placental disk from 049-103,

(B) secondary placental disk from 049-103, (C) primary placental disk from 049-102, and (D) secondary placental disk from 049-102. Scale bar = 1000 micrometers.

transmission in these studies we intentionally avoided any intrauterine sampling to ensure no confounding variables. Because vRNA was not detected in any fetal tissues, our results may suggest that vertical transmission did not occur between dam 049-101 and the developing fetus. Alternatively, the results may suggest immunologic elimination of virus at later gestational ages as previously suggested by a study using direct fetal ZIKV inoculation (43). Our decision to challenge the animals in this study early in pregnancy ( 30 days gestation) was based on findings in humans suggesting that during the first trimester, ZIKV infection is associated with a higher risk of adverse fetal and pregnancy outcomes $(27,43,50-53)$. In addition, we hypothesized that early pregnancy, possibly before a woman knows she is pregnant, may be a period of especially high risk for 


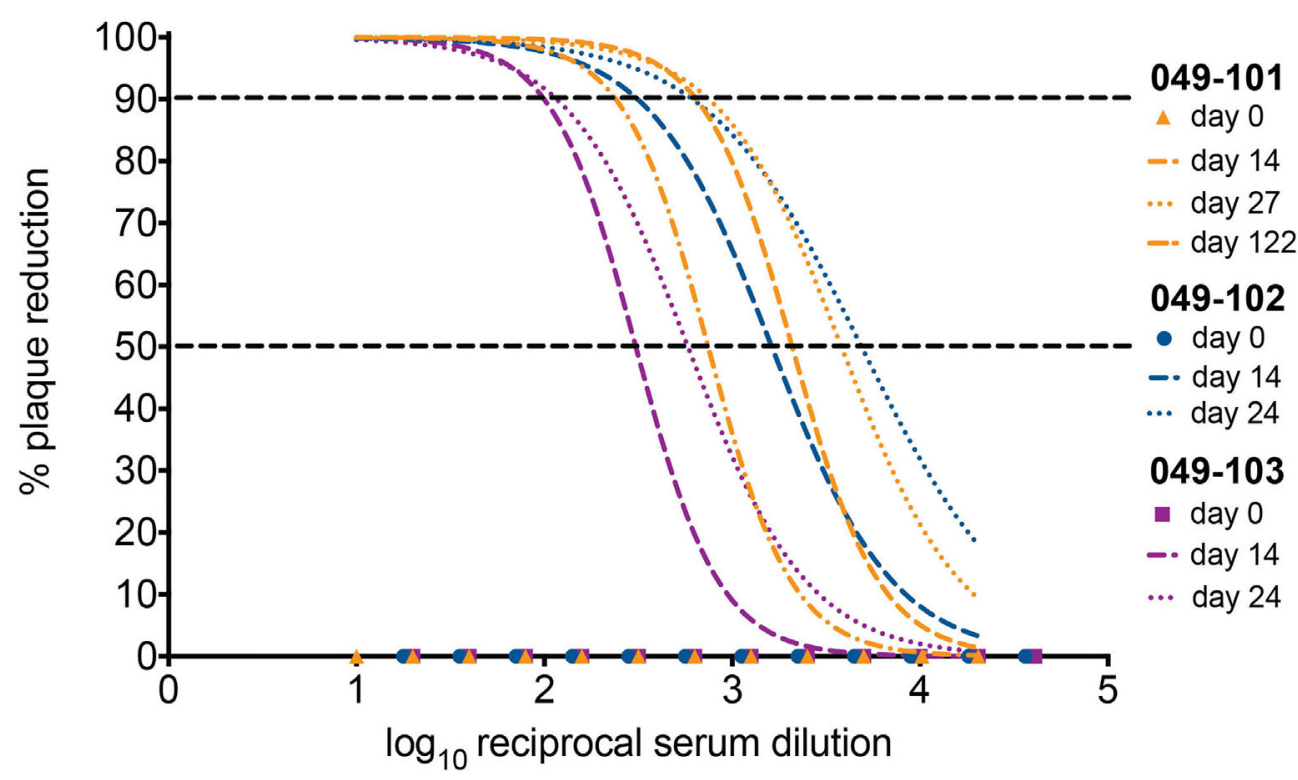

FIGURE 5 | All three dams developed neutralizing antibodies (nAbs) against ZIKV as detected by PRNT9o following intravaginal ZIKV infection. The X-axis is the log10 reciprocal serum dilution and the $y$-axis is the percent plaque reduction for ZIKV-DAK. Day 0 for all animals is shown as symbols with $049-101$ represented by orange triangles, 049-102 represented by blue circles, and 049-103 represented by magenta squares. Dashed gray horizontal lines indicate the $\mathrm{PRNT}_{90}$ and $\mathrm{PRNT}_{50}$ cut-offs, respectively. Neutralization curves were generated using non-linear regression to estimate the dilution of serum required to inhibit $90 \%$ of Vero cell culture infection. Neutralization curves are shown for days 14 (dashed lines) and 24 (dotted lines) for dams 049-102 (blue) and 049-103 (magenta), and for days 14, 27, and 122 (dashed and dotted line) for dam 049-101 (orange).

sexual transmission of ZIKV because precautions against this transmission route, such as condoms, may not be utilized (23, 24). Overall, our results suggest that sexual transmission of ZIKV during early pregnancy may represent a significant risk for adverse outcomes.

Our results indicating early demise as a result of ZIKV infection are consistent with those described previously in a cross-center, cross-NHP species study (29). Interestingly, our finding that 2 of $3(\sim 66 \%)$ pregnancies resulted in nonviable embryos following intravaginal ZIKV infection during early pregnancy represents a higher rate of loss than the $\sim 26 \%$ previously reported for NHP (29). We acknowledge this loss rate is based on small animal numbers and could change as more animals are studied. Despite this higher rate compared to other NHP models reported to date, both early gestation and near term reflect periods of higher rates of spontaneous loss for macaques (54). While the loss rate reported in our study may be higher than the background rate of early loss in humans during the first trimester, data are very limited regarding the rate at which ZIKVassociated loss occurs in humans during the first trimester. A rate of approximately $11 \%$ was recently reported in a study during a period of epidemic transmission in Manaus, Brazil (55-58), although as noted, in many cases women may not be aware of an early pregnancy, thus the rate of loss could actually be higher. Additional studies with larger animal numbers will be necessary to determine the impact of the challenge dose, virus isolate, gestational age, and route of infection on pregnancy loss and how this relates to rates of spontaneous loss in early gestation.
Some limitations of this study include the use of a relatively high dose of ZIKV to inoculate the dams, the inclusion of multiple challenges over a short timeframe, and the small number of animals included in the study. The dose of inoculum chosen for this study is representative of the high end of the ZIKV vRNA range reportedly detected in human semen, which can be up to 100,000 times higher than that in blood (16-18). In part, this dose was chosen due to the small number of animals included, our interest in the impact of intravaginal ZIKV exposure early in pregnancy, and the need to maximize chances of successful infection during early gestation. Previous studies in nonpregnant NHP have shown that intravaginal ZIKV inoculation results in successful infection after a single challenge approximately 33-75 percent of the time $(31,37,59)$. In pregnant olive baboons, a single intravaginal inoculation mid-gestation with semen containing ZIKV (originating from French Polynesia or Puerto Rico) resulted in 4 of 6 animals developing detectable vRNA in blood, with an additional animal having detectable vRNA in blood after a second inoculation (33). This was the rationale for the choice to perform repeat challenges at two-hour intervals in this study: in order to maximize the likelihood of establishing a productive infection in our small cohort within a single day. We acknowledge that it is difficult to determine whether the inoculation route played a significant role in our observed outcomes or whether the cumulative inoculum dose, virus isolate, timing of infection, or some combination of these factors played a role in the observed outcomes. Future studies 
modeling sexual transmission should aim to determine which of these factors significantly impact pregnancy outcome.

We chose to utilize a low passage African ZIKV isolate (ZIKV-DAK) rather than a more contemporary isolate such as the commonly utilized PRVABC59 because, although it is also low passage, recent studies have suggested that this virus may have an attenuated phenotype and is not as pathogenic as ZIKVDAK in mice $(41,60)$. In addition, ZIKV was first isolated from a febrile rhesus macaque in the Zika Forest near Entebbe, Uganda in 1947 (61, 62). Since that time, serologic and molecular (RNA or virus isolation) evidence of continued circulation in Africa has been intermittently reported in humans, animals, and mosquitoes (63-67). Prior to a report from Guinea-Bissau from 2016, during which an outbreak and subsequent identification of infant microcephaly cases was attributed to an African lineage virus, there were no reports of ZIKV impacting pregnancies and infant development in Africa $(63,68)$. This has led to a number of hypotheses as to why, which includes, but is not limited to the following: widespread immunity in populations of childbearing age due to infection earlier in life; masking of ZIKV-associated adverse outcomes due to a high number of other, co-circulating pathogens in many populations, such as malaria; or embryonic loss during very early pregnancy simply unrecognized due to unknown status or inconsistent access to prenatal care $(63,64,69)$. The data generated in this work supports the latter hypothesis of early loss. In reality, depending on the region, many of these factors could be playing an additive role in low and/or underreporting of ZIKV-associated pregnancy outcomes in Africa. Whether the early pregnancy losses observed in our study were due to increased pathogenicity of the African ZIKV isolate utilized relative to other isolates, the intravaginal route of infection, or both will require additional studies.

Many key questions remain with regard to understanding how different ZIKV geographic isolates may differentially impact pregnancy and fetal developmental outcomes. This study suggests that NHP models may be able to differentiate pregnancy outcomes between different isolates. Route of maternal infection may also play a role in pregnancy outcomes, at least in the case of NHP, as intravenous and intra-amniotic ZIKV infections in combination during pregnancy have been associated with a trend toward lower fetal survival rates across multiple studies compared to subcutaneous infections (29). However, both routes of ZIKV infection have been previously shown to result in early pregnancy loss in macaques, in particular when maternal infection occurred in the first trimester (29). Zika virus infection of common marmoset dams via an intramuscular route during the first or second trimesters has also been shown to result in spontaneous pregnancy loss (70). In the case of the marmosets, the timing of pregnancy loss (16-18 days post-infection) was very similar to that reported here for intravaginal inoculation (70). Overall, our study suggests that intravaginal infection during early pregnancy may also lower survival rates in macaques. Ultimately, our study was designed to balance all of the potential influential factors previously mentioned within the constraints of a proof-ofconcept study and the requirement for challenge and infection to occur during early pregnancy in order to evaluate this question.

Our results suggest that low passage, African lineage virus (ZIKV-DAK) has the potential to result in embryonic demise in rhesus macaques when infection occurs intravaginally and in early pregnancy. To our knowledge, this is the first NHP study to show clear evidence of vertical transmission of ZIKV following intravaginal infection, which has only previously been observed in mice $(20,30,36)$. NHP, due to susceptibility without immune modulation, as well as having significant similarities to human pregnancy, may provide better approximations for human infections than other animal models (71). Furthermore, this is the first NHP study to show that African lineage ZIKV infection during pregnancy has the potential to result in severe fetal outcomes. Taken together, our results suggest that additional attention should be given to ongoing perinatal surveillance in African communities and to promoting awareness regarding the risks of sexual transmission of ZIKV in endemic areas.

\section{DATA AVAILABILITY STATEMENT}

The raw data supporting the conclusions of this article will be made available by the authors, without undue reservation.

\section{ETHICS STATEMENT}

The animal study was reviewed and approved by University of California, Davis Institutional Animal Care and Use Committee.

\section{AUTHOR CONTRIBUTIONS}

$\mathrm{CN}, \mathrm{AT}, \mathrm{CM}$, and DHO designed the study. AT provided animal oversight and monitoring, ultrasound imaging, and performed all sample collections. AT and CM performed animal infections. AT, MM, MB, XZ, HS, TM, MA, EB analyzed samples. CN, DD, and JR curated data. $\mathrm{CN}$ and JR prepared the figures. $\mathrm{CN}$ prepared the initial manuscript draft. All authors contributed to the article and approved the submitted version.

\section{FUNDING}

DHHS/PHS/NIH R01 A|1116382-01A1, NIH P51 OD011107 and NIH S10 OD016261.

\section{ACKNOWLEDGMENTS}

We thank the research, animal care, and veterinary staff at the California National Primate Research Center for caring for the animals and supporting this study amid the emerging SARSCoV-2 pandemic. We also thank DHHS/PHS/NIH for providing 
the supplemental funding for R01 A1116382-01A1 that allowed this work to be completed. These studies were also supported by the California National Primate Research Center base operating grant \#OD011107. In vivo imaging was performed with instrumentation funded by an NIH S10 grant \#OD016261.

\section{REFERENCES}

1. Zika Cumulative Cases. PAHO. Available at: https://www.paho.org/hq/index. php?option $=$ com_content $\&$ view $=$ article $\&$ id $=12390:$ zika - cumulativecases\&Itemid=42090\&lang=en (Accessed March 22, 2021).

2. Moore CA, Staples JE, Dobyns WB, Pessoa A, Ventura CV, Fonseca EB da, et al. Characterizing the Pattern of Anomalies in Congenital Zika Syndrome for Pediatric Clinicians. JAMA Pediatr (2017) 171:288-95. doi: 10.1001/ jamapediatrics.2016.3982

3. van der Eijk AA, van Genderen PJ, Verdijk RM, Reusken CB, Mögling R, van Kampen JJA, et al. Miscarriage Associated With Zika Virus Infection. N Engl J Med (2016) 375:1002-4. doi: 10.1056/NEJMc1605898

4. Azevedo RSS, Araujo MT, Oliveira CS, Filho AJM, Nunes BTD, Henriques DF, et al. Zika Virus Epidemic in Brazil. II. Post-Mortem Analyses of Neonates With Microcephaly, Stillbirths, and Miscarriage. J Clin Med Res (2018) 7:496-508. doi: 10.3390/jcm7120496

5. Tabata T, Petitt M, Puerta-Guardo H, Michlmayr D, Wang C, Fang-Hoover J, et al. Zika Virus Targets Different Primary Human Placental Cells, Suggesting Two Routes for Vertical Transmission. Cell Host Microbe (2016) 20:155-66. doi: 10.1016/j.chom.2016.07.002

6. Gregory CJ, Oduyebo T, Brault AC, Brooks JT, Chung K-W, Hills S, et al. Modes of Transmission of Zika Virus. J Infect Dis (2017) 216:S875-83. doi: 10.1093/infdis/jix396

7. Counotte MJ, Kim CR, Wang J, Bernstein K, Deal CD, Broutet NJN, et al. Sexual Transmission of Zika Virus and Other Flaviviruses: A Living Systematic Review. PloS Med (2018) 15:e1002611. doi: 10.1371/journal.pmed.1002611

8. de Barros ACWG, Santos KG, Massad E, Coelho FC. Sex-Specific Asymmetrical Attack Rates in Combined Sexual-Vectorial Transmission Epidemics. Microorganisms (2019) 7:112-25. doi: 10.3390/microorganisms7040112

9. Foy BD, Kobylinski KC, Chilson Foy JL, Blitvich BJ, Travassos da Rosa A, Haddow AD, et al. Probable Non-Vector-Borne Transmission of Zika Virus, Colorado, USA. Emerg Infect Dis (2011) 17:880-2. doi: 10.3201/eid1705.101939

10. McCarthy M. Zika Virus was Transmitted by Sexual Contact in Texas, Health Officials Report. BMJ (2016) 352:i720. doi: 10.1136/bmj.i720

11. D’Ortenzio E, Matheron S, Yazdanpanah Y, de Lamballerie X, Hubert B, Piorkowski G, et al. Evidence of Sexual Transmission of Zika Virus. N Engl J Med (2016) 374:2195-8. doi: 10.1056/NEJMc1604449

12. Deckard DT, Chung WM, Brooks JT, Smith JC, Woldai S, Hennessey M, et al. Male-to-Male Sexual Transmission of Zika Virus-Texas, January 2016. MMWR Morb Mortal Wkly Rep (2016) 65:372-4. doi: 10.15585/mmwr.mm6514a3

13. Davidson A, Slavinski S, Komoto K, Rakeman J, Weiss D. Suspected Femaleto-Male Sexual Transmission of Zika Virus - New York City, 2016. MMWR Morb Mortal Wkly Rep (2016) 65:716-7. doi: 10.15585/mmwr.mm6528e2

14. Yarrington CD, Hamer DH, Kuohung W, Lee-Parritz A. Congenital Zika Syndrome Arising From Sexual Transmission of Zika Virus, a Case Report. Fertil Res Pract (2019) 5:1. doi: 10.1186/s40738-018-0053-5

15. Turmel JM, Abgueguen P, Hubert B, Vandamme YM, Maquart M, Le Guillou-Guillemette $\mathrm{H}$, et al. Late Sexual Transmission of Zika Virus Related to Persistence in the Semen. Lancet (2016) 387:2501. doi: 10.1016/ S0140-6736(16)30775-9

16. Musso D, Richard V, Teissier A, Stone M, Lanteri MC, Latoni G, et al. Recipient Epidemiology and Donor Evaluation Study (Reds-III) ZIKV Study Group. Detection of Zika Virus RNA in Semen of Asymptomatic Blood Donors. Clin Microbiol Infect (2017) 23:1001.e1-3. doi: 10.1016/j.cmi.2017.07.006

17. Mead PS, Duggal NK, Hook SA, Delorey M, Fischer M, Olzenak McGuire D, et al. Zika Virus Shedding in Semen of Symptomatic Infected Men. N Engl J Med (2018) 378:1377-85. doi: 10.1056/NEJMoa1711038

18. Mansuy JM, Dutertre M, Mengelle C, Fourcade C, Marchou B, Delobel P, et al. Zika Virus: High Infectious Viral Load in Semen, a New Sexually Transmitted Pathogen? Lancet Infect Dis (2016) 16:405. doi: 10.1016/S1473-3099(16)00138-9

\section{SUPPLEMENTARY MATERIAL}

The Supplementary Material for this article can be found online at: https://www.frontiersin.org/articles/10.3389/fimmu.2021. 686437/full\#supplementary-material

19. McDonald EM, Duggal NK, Brault AC. Pathogenesis and Sexual Transmission of Spondweni and Zika Viruses. PloS Negl Trop Dis (2017) 11:e005990. doi: 10.1371/journal.pntd.0005990

20. Duggal NK, Ritter JM, Pestorius SE, Zaki SR, Davis BS, Chang G-JJ, et al. Frequent Zika Virus Sexual Transmission and Prolonged Viral RNA Shedding in an Immunodeficient Mouse Model. Cell Rep (2017) 18:1751-60. doi: 10.1016/j.celrep.2017.01.056

21. Rosenberg ES, Doyle K, Munoz-Jordan JL, Klein L, Adams L, Lozier M, et al. Prevalence and Incidence of Zika Virus Infection Among Household Contacts of Patients With Zika Virus Disease, Puerto Rico, 2016-2017. J Infect Dis (2019) 220:932-9. doi: 10.1093/infdis/jiy689

22. Racicot K, Cardenas I, Wünsche V, Aldo P, Guller S, Means RE, et al. Viral Infection of the Pregnant Cervix Predisposes to Ascending Bacterial Infection. J Immunol (2013) 191:934-41. doi: 10.4049/jimmunol.1300661

23. Teasdale CA, Abrams EJ, Chiasson MA, Justman J, Blanchard K, Jones HE. Sexual Risk and Intravaginal Practice Behavior Changes During Pregnancy. Arch Sex Behav (2017) 46:539-48. doi: 10.1007/s10508-016-0818-z

24. Salvesen von Essen B, Kortsmit K, Warner L, D’Angelo DV, Shulman HB, Virella WH, et al. Preventing Sexual Transmission of Zika Virus Infection During Pregnancy, Puerto Rico, USA, 20161. Emerg Infect Dis (2019) 25:2115-9. doi: 10.3201/eid2511.190915

25. Hoen B, Schaub B, Funk AL, Ardillon V, Boullard M, Cabié A, et al. Pregnancy Outcomes After ZIKV Infection in French Territories in the Americas. N Engl J Med (2018) 378:985-94. doi: 10.1056/NEJMoa1709481

26. Lin HZ, Tambyah PA, Yong EL, Biswas A, Chan S-Y. A Review of Zika Virus Infections in Pregnancy and Implications for Antenatal Care in Singapore. Singapore Med J (2017) 58:171-8. doi: 10.11622/smedj.2017026

27. Kleber de Oliveira W, Cortez-Escalante J, De Oliveira WTGH, do Carmo GMI, Henriques CMP, Coelho GE, et al. Increase in Reported Prevalence of Microcephaly in Infants Born to Women Living in Areas With Confirmed Zika Virus Transmission During the First Trimester of Pregnancy - Brazil, 2015. MMWR Morb Mortal Wkly Rep (2016) 65:242-7. doi: 10.15585/mmwr. $\mathrm{mm} 6509 \mathrm{e} 2$

28. Pomar L, Malinger G, Benoist G, Carles G, Ville Y, Rousset D, et al. Association Between Zika Virus and Fetopathy: A Prospective Cohort Study in French Guiana. Ultrasound Obstet Gynecol (2017) 49:729-36. doi: 10.1002/uog.17404

29. Dudley DM, Van Rompay KK, Coffey LL, Ardeshir A, Keesler RI, BlissMoreau E, et al. Miscarriage and Stillbirth Following Maternal Zika Virus Infection in Nonhuman Primates. Nat Med (2018) 24:1104-7. doi: 10.1038/ s41591-018-0088-5

30. Duggal NK, McDonald EM, Ritter JM, Brault AC. Sexual Transmission of Zika Virus Enhances In Utero Transmission in a Mouse Model. Sci Rep (2018) 8:4510. doi: 10.1038/s41598-018-22840-6

31. Haddow AD, Perez-Sautu U, Wiley MR, Miller LJ, Kimmel AE, Principe LM, et al. Modeling Mosquito-Borne and Sexual Transmission of Zika Virus in an Enzootic Host, the African Green Monkey. PloS Negl Trop Dis (2020) 14: e0008107. doi: 10.1371/journal.pntd.0008107

32. Schmidt JK, Mean KD, Puntney RC, Alexander ES, Sullivan R, Simmons HA, et al. Zika Virus in Rhesus Macaque Semen and Reproductive Tract Tissues: A Pilot Study of Acute Infection†. Biol Reprod (2020) 103:1030-42. doi: 10.1093/biolre/ioaa137

33. Gurung S, Nadeau H, Maxted M, Peregrine J, Reuter D, Norris A, et al Maternal Zika Virus (Zikv) Infection Following Vaginal Inoculation With ZIKV-Infected Semen in Timed-Pregnant Olive Baboons. J Virol (2020) 94:116. doi: 10.1128/JVI.00058-20

34. Peregrine J, Gurung S, Lindgren MC, Husain S, Zavy MT, Myers DA, et al. Zika Virus Infection, Reproductive Organ Targeting, and Semen Transmission in the Male Olive Baboon. J Virol (2019) 94:1-16. doi: 10.1128/JVI.01434-19

35. Woollard SM, Olwenyi OA, Dutta D, Dave RS, Mathews S, Gorantla S, et al. Preliminary Studies on Immune Response and Viral Pathogenesis of Zika 
Virus in Rhesus Macaques. Pathogens (2018) 7:70-81. doi: 10.3390/ pathogens7030070

36. Winkler CW, Woods TA, Rosenke R, Scott DP, Best SM, Peterson KE. Sexual and Vertical Transmission of Zika Virus in Anti-Interferon Receptor-Treated Rag1-Deficient Mice. Sci Rep (2017) 7:7176. doi: 10.1038/s41598-017-07099-7

37. Carroll T, Lo M, Lanteri M, Dutra J, Zarbock K, Silveira P, et al. Zika Virus Preferentially Replicates in the Female Reproductive Tract After Vaginal Inoculation of Rhesus Macaques. PloS Pathog (2017) 13:e1006537. doi: 10.1371/journal.ppat.1006537

38. Tang WW, Young MP, Mamidi A, Regla-Nava JA, Kim K, Shresta S. A Mouse Model of Zika Virus Sexual Transmission and Vaginal Viral Replication. Cell Rep (2016) 17:3091-8. doi: 10.1016/j.celrep.2016.11.070

39. Yockey LJ, Varela L, Rakib T, Khoury-Hanold W, Fink SL, Stutz B, et al. Vaginal Exposure to Zika Virus During Pregnancy Leads to Fetal Brain Infection. Cell (2016) 166:1247-56.e4. doi: 10.1016/j.cell.2016.08.004

40. TA F. Ultrasound Imaging in Rhesus (Macaca mulatta) and Long-Tailed (Macaca fascicularis) Macaques: Reproductive and Research Applications. Lab Primate (2005), 317-52. doi: 10.1016/b978-012080261-6/50020-9

41. Jaeger AS, Murrieta RA, Goren LR, Crooks CM, Moriarty RV, Weiler AM, et al. Zika Viruses of African and Asian Lineages Cause Fetal Harm in a Mouse Model of Vertical Transmission. PloS Negl Trop Dis (2019) 13: e0007343. doi: 10.1371/journal.pntd.0007343

42. Dudley DM, Aliota MT, Mohr EL, Weiler AM, Lehrer-Brey G, Weisgrau KL, et al. A Rhesus Macaque Model of Asian-lineage Zika Virus Infection. Nat Commun (2016) 7:12204. doi: 10.1038/ncomms12204

43. Tarantal AF, Hartigan-O'Connor DJ, Penna E, Kreutz A, Martinez ML, Noctor SC. Fetal Rhesus Monkey First Trimester Zika Virus Infection Impacts Cortical Development in the Second and Third Trimesters. Cereb Cortex (2020) 31:2309-21. doi: 10.1093/cercor/bhaa336

44. Koenig MR, Razo E, Mitzey A, Newman CM, Dudley DM, Breitbach ME, et al. Quantitative Definition of Neurobehavior, Vision, Hearing and Brain Volumes in Macaques Congenitally Exposed to Zika Virus. PloS One (2020) 15:e0235877. doi: 10.1371/journal.pone.0235877

45. Breitbach ME, Newman CM, Dudley DM, Stewart LM, Aliota MT, Koenig MR, et al. Primary Infection With Dengue or Zika Virus Does Not Affect the Severity of Heterologous Secondary Infection in Macaques. PloS Pathog (2019) 15:e1007766. doi: 10.1371/journal.ppat.1007766

46. Lindsey HS, Calisher CH, Mathews JH. Serum Dilution Neutralization Test for California Group Virus Identification and Serology. J Clin Microbiol (1976) 4:503-10.

47. Crooks CM, Weiler AM, Rybarczyk SL, Bliss M, Jaeger AS, Murphy ME, et al. African-Lineage Zika Virus Replication Dynamics and Maternal-Fetal Interface Infection in Pregnant Rhesus Macaques. Cold Spring Harbor Lab (2020). doi: 10.1101/2020.11.30.405670

48. Nguyen SM, Antony KM, Dudley DM, Kohn S, Simmons HA, Wolfe B, et al. Highly Efficient Maternal-Fetal Zika Virus Transmission in Pregnant Rhesus Macaques. PloS Pathog (2017) 13:e1006378. doi: 10.1371/journal.ppat.1006378

49. Mohr EL, Block LN, Newman CM, Stewart LM, Koenig M, Semler M, et al. Ocular and Uteroplacental Pathology in a Macaque Pregnancy With Congenital Zika Virus Infection. PloS One (2018) 13:e0190617. doi: 10.1371/journal.pone.0190617

50. Honein MA, Dawson AL, Petersen EE, Jones AM, Lee EH, Yazdy MM, et al. Birth Defects Among Fetuses and Infants of US Women With Evidence of Possible Zika Virus Infection During Pregnancy. JAMA (2017) 317:59-68. doi: 10.1001/jama.2016.19006

51. Peña F, Pimentel R, Khosla S, Mehta SD, Brito MO. Zika Virus Epidemic in Pregnant Women, Dominican Republic, 2016-2017. Emerg Infect Dis (2019) 25:247-55. doi: 10.3201/eid2502.181054

52. Ospina ML, Tong VT, Gonzalez M, Valencia D, Mercado M, Gilboa SM, et al. Zika Virus Disease and Pregnancy Outcomes in Colombia. N Engl J Med (2020) 383:537-45. doi: 10.1056/NEJMoa1911023

53. Ades AE, Soriano-Arandes A, Alarcon A, Bonfante F, Thorne C, Peckham CS, et al. Vertical Transmission of Zika Virus and its Outcomes: A Bayesian Synthesis of Prospective Studies. Lancet Infect Dis (2020) 21:537-45. doi: 10.1016/S1473-3099(20)30432-1

54. Hendrie TA, Peterson PE, Short JJ, Tarantal AF, Rothgarn E, Hendrie MI, et al. Frequency of Prenatal Loss in a Macaque Breeding Colony. Am J Primatol (1996) 40:41-53. doi: 10.1002/(SICI)1098-2345(1996)40:1<41::AID-AJP3>3.0.CO;2-0
55. Brasil P, Pereira JP Jr, Moreira ME, Ribeiro Nogueira RM, Damasceno L, Wakimoto M, et al. Zika Virus Infection in Pregnant Women in Rio De Janeiro. N Engl J Med (2016) 375:2321-34. doi: 10.1056/NEJMoa1602412

56. Cohain JS, Buxbaum RE, Mankuta D. Spontaneous First Trimester Miscarriage Rates Per Woman Among Parous Women With 1 or More Pregnancies of 24 Weeks or More. BMC Pregnancy Childbirth (2017) 17:437. doi: 10.1186/s12884-017-1620-1

57. Redivo E de F, Bôtto Menezes C, da Costa Castilho M, Brock M, da Silva Magno E, Gomes Saraiva M das G, et al. Zika Virus Infection in a Cohort of Pregnant Women With Exanthematic Disease in Manaus, Brazilian Amazon. Viruses (2020) 12:1362-77. doi: 10.3390/v12121362

58. Oliver A, Overton C. Diagnosis and Management of Miscarriage. Practitioner (2014) 258:25-8.

59. Haddow AD, Nalca A, Rossi FD, Miller LJ, Wiley MR, Perez-Sautu U, et al. High Infection Rates for Adult Macaques After Intravaginal or Intrarectal Inoculation With Zika Virus. Emerg Infect Dis (2017) 23:1274-81. doi: 10.3201/eid2308.170036

60. Duggal NK, McDonald EM, Weger-Lucarelli J, Hawks SA, Ritter JM, Romo H, et al. Mutations Present in a Low-Passage Zika Virus Isolate Result in Attenuated Pathogenesis in Mice. Virology (2019) 530:19-26. doi: 10.1016/ j.virol.2019.02.004

61. Dick GWA, Kitchen SF, Haddow AJ. Zika Virus. I. Isolations and Serological Specificity. Trans R Soc Trop Med Hyg (1952) 46:509-20. doi: 10.1016/00359203(52)90042-4

62. Dick GWA. Zika Virus. II. Pathogenicity and Physical Properties. Trans R Soc Trop Med Hyg (1952) 46:521-34. doi: 10.1016/0035-9203(52)90043-6

63. Nutt C, Adams P. Zika in Africa-the Invisible Epidemic? Lancet (2017) 389:1595-6. doi: 10.1016/S0140-6736(17)31051-6

64. Marchi S, Viviani S, Montomoli E, Tang Y, Boccuto A, Vicenti I, et al. Zika Virus in West Africa: A Seroepidemiological Study Between 2007 and 2012. Viruses (2020) 12:641-70. doi: 10.3390/v12060641

65. McCrae AW, Kirya BG. Yellow Fever and Zika Virus Epizootics and Enzootics in Uganda. Trans R Soc Trop Med Hyg (1982) 76:552-62. doi: 10.1016/00359203(82)90161-4

66. Dick GW. Epidemiological Notes on Some Viruses Isolated in Uganda; Yellow Fever, Rift Valley Fever, Bwamba Fever, West Nile, Mengo, Semliki Forest, Bunyamwera, Ntaya, Uganda S and Zika Viruses. Trans $R$ Soc Trop Med Hyg (1953) 47:13-48. doi: 10.1016/0035-9203(53)90021-2

67. Kirya BG. A Yellow Fever Epizootic in Zika Forest, Uganda, During 1972: Part 1: Virus Isolation and Sentinel Monkeys. Trans R Soc Trop Med Hyg (1977) 71:254-60. doi: 10.1016/0035-9203(77)90020-7

68. Rosenstierne MW, Schaltz-Buchholzer F, Bruzadelli F, Có A, Cardoso P, Jørgensen CS, et al. Zika Virus Igg in Infants With Microcephaly, GuineaBissau, 2016. Emerg Infect Dis (2018) 24:948-50. doi: 10.3201/eid2405.180153

69. Sheridan MA, Yunusov D, Balaraman V, Alexenko AP, Yabe S, VerjovskiAlmeida S, et al. Vulnerability of Primitive Human Placental Trophoblast to Zika Virus. Proc Natl Acad Sci USA (2017) 114:E1587-96. doi: 10.1073/ pnas. 1616097114

70. Seferovic M, Sánchez-San Martín C, Tardif SD, Rutherford J, Castro ECC, $\mathrm{Li}$ T, et al. Experimental Zika Virus Infection in the Pregnant Common Marmoset Induces Spontaneous Fetal Loss and Neurodevelopmental Abnormalities. Sci Rep (2018) 8:6851. doi: 10.1038/s41598-018-25205-1

71. Dudley DM, Aliota MT, Mohr EL, Newman CM, Golos TG, Friedrich TC, et al. Using Macaques to Address Critical Questions in Zika Virus Research. Annu Rev Virol (2019) 6:481-500. doi: 10.1146/annurev-virology-092818-015732

Conflict of Interest: The authors declare that the research was conducted in the absence of any commercial or financial relationships that could be construed as a potential conflict of interest.

Copyright (® 2021 Newman, Tarantal, Martinez, Simmons, Morgan, Zeng, Rosinski, Bliss, Bohm, Dudley, Aliota, Friedrich, Miller and O'Connor. This is an open-access article distributed under the terms of the Creative Commons Attribution License (CC BY). The use, distribution or reproduction in other forums is permitted, provided the original author(s) and the copyright owner(s) are credited and that the original publication in this journal is cited, in accordance with accepted academic practice. No use, distribution or reproduction is permitted which does not comply with these terms. 